\title{
Safety concerns of Probiotic use: A review
}

\author{
Suresh KS, Srinath Krishnappa, Pravesh Bhardwaj
}

\begin{abstract}
Every day, millions of people consume probiotics for their perceived health benefits, but how safe are probiotics? Do probiotics cause invasive infection and if so, who is at risk? There is considerable interest in probiotics for a variety of medical conditions, and millions of people around the world consume probiotics daily for perceived health benefits. Lactobacilli, bifidobacteria, and lactococci have generally been regarded as safe. There are 3 theoretical concerns regarding the safety of probiotics: (a) the occurrence of disease, such as bacteremia or endocarditis; (b) toxic or metabolic effects on the gastrointestinal tract; and (c) the transfer of antibiotic resistance in the gastrointestinal flora. So, in order to deliver appropriate probiotic therapy both medical and dental practitioners should be aware of the adverse effects associated with probiotic use
\end{abstract}

\section{Introduction}

Probiotics can be defined as "An oral supplement or a food product that contains a sufficient number of viable microorganisms to alter the microflora of the host $\&$ has the potential for beneficial health effects" $(1,2$, $3)$. It can also be defined as "Live microorganisms that when administered in adequate amounts confer a health benefit on the host" (4). Most of the commercially available probiotics belong to the Lactobacillus \& Bifidobacterium species, that are part of normal heathy gastrointestinal mico biota $(5,6,7,8)$.

Probiotic effects are strain specific, thus each individual bacterial strain must be tested separately for health benefit in question, and the effects described for one strain cannot be directly applied to others (9). Lactobacilli fall into the category of organisms classified as "generally regarded as safe" (10). Organisms that are regarded as safe along with lactobacilli, are lactococci, bifidobacterium and yeast. There are other probiotic organisms, such as enterococcus, bacillus, and other spore forming bacteria, as well as streptococci, that are not generally regarded as safe but have been used as probiotics. In this review, we will focus on the data regarding the safety of probiotics.

\section{Risk factors associated with the use of Probiotics}

The abilities of probiotics to survive and be metabolically active in the gastrointestinal(g.i) tract and to interact with the gastrointestinal mucosa and gastrointestinal microflora have led to 4 areas of concern about safety (11).

1. Potential for bacteria to translocate/transmigrate, crossing the g.i.barrier and resulting in invasive infection.

2. The possibility for some probiotic organisms to harbour resistance to antibiotics, leading to a potential for antibiotic resistance to be transferred from probiotic bacteria to other potentially pathogenic bacteria (12, 13).

3. Metabolic activity and immunologic effects of probiotics leading to possible deleterious metabolic effects and excessive immune stimulation $(12,14,15,16)$.

4. Finally we have concerns about product quality, since products that do not contain the probiotic on the label, or that contain contaminants may also place the consumer at risk.

Probiotics are generally considered safe when ingested orally or used vaginally and are well tolerated. One safety concern associated with probiotics is the potential for these organisms to cause systemic infections. Although rare, probiotic related bacteremia and fungemia have been reported (17). It is estimated that the risk of developing bacteremia from ingested Lactobacillus probiotics is less than 1 per 1million users (18), and the risk of developing fungemia from Saccharomyces boulardii is estimated at 1 per 5.6million users, and is estimated to be lower in healthy individuals (19).

\section{Risk of bacterial translocation/transmigration}

Translocation by intestinal bacteria is facilitated by numerous factors including intestinal mucosal injury, immunodeficiency, gut prematurity and abnormal bacterial flora $(20,21)$, as well as adherence of the bacteria to the mucosal surface (22). Risk factors for translocation have been studied in the mouse model. Zhou et al evaluated whether 3 probiotics, Lactobacillus rhamnosus HN001(DR20)TM, Lactobacillus acidophilus HN017 and Bifidobacterium lactis HN019(DR10) could translocate and cause invasive infection in an oral mouse model $(23,24)$. On the other hand, according to one study, there is no increase in the translocation of other bacteria when probiotics are given (25). In addition, probiotics mitigate the translocation of pathogens 
during their use (26). There is no evidence, from population based studies, of any increased risk of bacteremia or endocarditis due to probiotics (27).

Table 1--

Risk of transfer of antimicrobial resistance

The antibiotic resistance gene can be transferred by conjugation, transduction or transformation (29). At present, reports regarding the spread of antibiotic resistance among Lactic acid bacteria and Bifidobacteria suggest that resistant strains from human and animal colons are rather common, that confirms the transfer of resistances between commensal organism in the complex ecosystem of g.i.tract (30). There is a general concern that such microbes may harbour genes that may contribute to opportunistic infections (31).

\section{Gastrointestinal toxicity studies}

Due to potential impact of the use of probiotics on gastrointestinal physiology, there can be production of metabolites that are undesirable, especially in patients with short small bowel syndrome (32). There is a theoretical risk that the probiotic bacteria might lead to malabsorption due to de-conjugation of bile salts (33, $34)$. This might, therefore, increase the risk of colon cancer $(34,35)$.

\section{Bacteremia and endocarditis potential}

Organisms that have been associated with endocarditis or bacteremia includes L. rhamnosis, L. plantarum, L. casei, L. paracasei, L. salivarius, L. acidophilus and many other lactobacilli $(34,36)$. In addition to this, Lactococcus lactis and Leuconostoc species, as well as pediococcus species have been demonstrated to cause bacteremia and endocarditis (34). Bifidobacterium species have also been isolated from the blood and in patients with endocarditis $(34,37)$.

\section{Risk of inadequate quality standards for Probiotics}

Quality of probiotic products is a matter of great concern. Temmerman et al (38) studied 55 european products 30 dried food supplements and 25 dairy products. No viable strains could be isolated from 11 (37\%) of the dried food supplements, 15 either had more probiotic species isolated than were listed on the product label or contained species not listed on the product label. In only $4(13 \%)$, did the probiotic product label match the contents.

\section{Safety of S.boulardii as probiotic}

Since the 1950s, S.boulardii has been used internationally \& extensively as a probiotic (39). Studies of S.boulardii in populations other than the healthy general public have demonstrated its efficacy for reducing recurrence of Clostridium difficle infection (CDI) when used in combination with standard therapy. A multicenter, double blind, placebo controlled trial investigated the effects of S.boulardii (1g/day) for 4 weeks in combination with vancomycin (high dose $2 \mathrm{~g} /$ day or low dose $500 \mathrm{mg} /$ day) or metronidazole (1g/day) to patients with either initial or recurrent CDI $(34,40)$. Recurrence rates were $16.7 \%$ for patients receiving S.boulardii with high dose vancomycin compared with $50 \%$ for patients receiving high dose vancomycin \& placebo $(\mathrm{p}=0.04)$ $(34,40)$.

\section{Safety of Lactobacillus rhamnosis GG}

Over a period of time, it has been administered to children with chronic inflammatory disease, including crohn's disease and juvenile rheumatoid arthritis, to adults with inflammatory bowel disease, and to patients with HIV infection (41). Till date, no significant adverse events have been demonstrated in these and other controlled trials (42). Factors ensuring the safety of lactobacillus GG, includes absence of plasmids, good enzyme profile as it elaborates beta-glucuronidase and urease, and it also secretes an antimicrobial agent (43, 44). In conclusion, lactobacillus GG has been proven safe both invitro and invivo, as well as in a number of human studies $(42,45)$. Although there have been rare cases of bacteremia and liver abscess in patients with short gut syndrome, overall, it is a safe probiotic.

\section{Genetically engineered probiotics}

Genetic modification of probiotics has been undertaken to increase certain physiologic or immunologic properties within the organism and to use the probiotic as a mucosal delivery system or a vaccine vector $(17,43)$. Their use is limited. 


\section{Steps to monitor safety of probiotics}

To monitor the safety of probiotics as they are introduced and increasingly used around the world, it is important to conduct population based surveillance for the isolation of probiotic bacteria from patients with infection. There should be knowledge of the susceptibility profile for any strain used in clinical trials $(17,46$, 47).

\section{Significance of probiotic safety in dentistry}

Probiotics are widely used in dentistry mainly in prevention of dental caries, periodontal diseases, halitosis $(48,49,50,51)$. Till date only few studies were reported in relation to safety of probiotics in the field of dentistry. Mackay et al (52) reported the development of L. rhamnosus endocarditis (strain not specified) after a dental extraction in a 67 year old man with mitral regurgitation who was taking probiotic capsules daily. More studies in this discipline can contribute towards probiotic safety issues in dentistry.

\section{Conclusion}

Overall probiotic use is safe in most of the cases. However, probiotic use should be avoided in patients having abnormal gastrointestinal mucosal barrier, children having short gut syndrome, immunocompromised patients, patients with central venous catheters, we also conclude that there is risk of plasmid mediated transfer of antibiotic resistance in some probiotic strains. Careful risk assessment for patients and proper handling of the probiotic during administration need to be conducted before using probiotics as drugs in institutional setting. Vigilant reporting of adverse events resulting from probiotic use is necessary to establish the safety profile of these agents when they are used in other than healthy populations.

\section{$>$ Why this paper is important to paediatric dentists}

This review highlights the safety concerns of probiotics in detail. Probiotics are used very frequently by the dentists especially pediatric dentists for the prevention of dental caries. So it is of utmost importance for the pediatric dentists to know about the risk factors associated with probiotic use and this review puts more light on this particular aspect of probiotic use.

\section{References}

[1]. Food and Agriculture Organization of the United Nations; World Health Organization. Guidelines for the evaluation of probiotics in food: joint $\mathrm{FAO} / \mathrm{WHO}$ Working Group report on drafting guidelines for the evaluation of probiotics in food. Available at: $\mathrm{ftp}: / / \mathrm{ftp}$.fao.org/es/esn/food/wgreport2.

[2]. pdf. Accessed October 1,2010

[3]. Food and Agriculture Organization of the United Nations; World Health Organization. Health and nutritional properties of probiotics in food including powder milk with live lactic acid bacteria: report of a joint FAO/WHO expert consultation on evaluation of health and nutritional properties of probiotics in food including powder milk with live lactic acid bacteria.Availableat: www.who.int/foodsafety/publications/fs_management/en/probiotics.pdf. Accessed October 1, 2010

[4]. Council for Agricultural Science and Technology. Probiotics: Their Potential to Impact Human Health. Ames, IA: Council for Agricultural Science and Technology; 2007. Available at: www.cast-science. org/websiteUploads/publicationPDFs/CAST\%20Probiotics\%20Issue\%20Paper\%20FINAL144.pdf. Accessed October 1, 2010

[5]. FAO/WHO. Guidelines for the evaluation of probiotics in Internet:http://www.who.int/foodsafety/fs_management/en/probiotic_guidelines.pdf (accessed 22 March 2006).

[6]. N. Ishibashi, S. Yamazaki, "Probiotics and safety", Am J Clin Nutr., 73(2 Suppl), 465S-470S (2001).

[7]. K.M. Tuohy, H.M. Probert et al., "Using probiotics and prebiotics to improve gut health", Drug Discov Today, 8(15), pp. 692-70 (2003).

[8]. Tomasik PJ and Tomasik P: Probiotics and prebiotics. Cereal Chem 80: 113-117, 2003.

[9]. Haukioja A, Yli-Knuuttila H, Loimaranta V, Kari K, Ouwehand

[10]. AC, Meurman JH, et al. Oral adhesion and survival of probiotic and other lactobacilli and bifidobacteria in vitro. Oral Microbiol Immunol. 2006;21(5):326-32.

[11]. de Vrese M, Schrezenmeir J. Probiotics, prebiotics, and synbiotics. Adv Biochem Eng Biotechnol 2008;111:1-66.

[12]. Joint FAO/WHOWorking Group on Drafting Guidelines for the Evaluation of Probiotics in Food. Guidelines for the evaluation of probiotics in food: report of a Joint FAO/WHO Working Group on Drafting Guidelines for the Evaluation of Probiotics in Food, London Ontario, Canada, April 30 and May 1, 2002. Available at: http:// www.who.int/foodsafety/publications/fs management/probiotics2/ en/index.html. Accessed 26 November 2007.

[13]. Food and Agriculture Organization of the United Nations and

[14]. World Health Organization, "Health and Nutritional Properties of Probiotics", Food including Powder Milk with Live Lactic Acid Bacteria, ftp://ftp.fao.org/es/esn/food/probio_report_en.pdf. 2001.

[15]. A.C. Senok, A.Y. Ismaeel et al., "Probiotics: facts and myths", Clin Microbiol Infect., 11(12), pp. 958-966 (2005).

[16]. A.A. Salyers, A. Gupta et al., "Human intestinal bacteria as

[17]. Reservoirs for antibiotic resistance genes", Trends Microbiol., 12(9), pp. $412-416$ (2004).

[18]. N. Ishibashi, S. Yamazaki, "Probiotics and safety", Am J Clin Nutr., 73(2 Suppl), 465S-470S (2001).

[19]. M. Saarela, G. Mogensen et al., "Probiotic bacteria: safety, Functional and technological properties", J Biotechnol., 84(3), pp. 197215 (2000).

[20]. A. Henriksson, T. Borody et al., "Probiotics under the regulatory microscope", Expert Opin Drug Saf., 4(6), pp. 1135-1143 (2005).

[21]. Snydman DR. The safety of probiotics. Clin Infect Dis 2008;46(Suppl 2):S104-11.

[22]. Borriello SP, Hammes WP, Holzapfel W, Marteau P, Schrezenmeir J, Vaara M, et al. Safety of probiotics that contain lactobacilli or bifidobacteria. Clin Infect Dis 2003;36(6):775-80. Epub 2003 Mar 5. 
[23]. Karpa KD. Probiotics for Clostridium difficile diarrhea: putting it into perspective. Ann Pharmacother 2007;41(7):1284-7. Epub 2007 Jun 26

[24]. R.D. Berg, E. Wommack et al., "Immunosuppression and intestinal bacterial overgrowth synergistically promote bacterial translocation", Arch Surg., 123(11), pp. 1359-1364 (1988).

[25]. E.A. Deitch, K. Maejima et al., "Effect of oral antibiotics and bacterial overgrowth on the translocation of the GI tract microflora in burned rats", J Trauma, 25(5), pp. 385-392 (1985).

[26]. B.S. Reddy, J. MacFie et al., "Commensal bacteria do translocate across the intestinal barrier in surgical patients", Clin Nutr., 26(2), pp. 208-215 (2007).

[27]. J.S. Zhou, Q. Shu et al., "Acute oral toxicity and bacterial Translocation studies on potentially probiotic strains of lactic acid bacteria", Food Chem Toxicol., 38(2-3), pp. 153-161 (2000).

[28]. J.S. Zhou, Q. Shu et al., "Safety assessment of potential probiotic lactic acid bacterial strains Lactobacillus rhamnosus HN001, Lb. acidophilus HN017, and Bifidobacterium lactis HN019 in BALB/c mice", Int J Food Microbiol., 56(1), pp. 87-96 (2000).

[29]. Yamazaki S, Machii K, Tsuyuki S, Momose H, Kawashima T, Ueda K. Immunological responses to monoassociated Bifidobacterium longum and their relation to prevention of bacterial invasion. Immunology 1985; 56:43-50.

[30]. McNaught CE, Woodcock NP, MacFie J, Mitchell CJ. A Prospective randomised study of the probiotic Lactobacillus plantarum $299 \mathrm{~V}$ on indices of gut barrier function in elective surgical patients. Gut 2002; 51:827-31.

[31]. Vesterlund S, Paltta J, Karp M, Ouwehand AC. Adhesion of bacteria to resected human colonic tissue: quantitative analysis of bacterial adhesion and viability. Res Microbiol 2005; 156:238-44.

[32]. Mogensen, G. 2003. Safety aspects of fermented products. In: Bulletin of International Dairy Federation. Brussels, Belgium. 144158.

[33]. Salyers, A.A., Shoemaker, N.B. and Schlesinger, D. 2008. Ecology of antibiotic resistance genes. In: Wax, R.G., Taber, H., Salyers, A.A. and Lewis, K.editors. (eds.): Bacterial resistance to antimicrobials. 2nd ed. CRC press: 436-445.

[34]. Ammor, M.S., Belén Flórez, A. and Mayo, B. 2007. Antibiotic resistance in non-enterococcal lactic acid bacteria and bifidobacteria. Food Microbiology 24 (6): 559-570.

[35]. Tompkins, T.A., Hagen, K.E., Wallace, T.D. and Fillion-Forté, V. 2008. Safety evaluation of two bacterial strains used in asian probiotic products. Canadian Journal of Microbiology 54 (5): 391-400.

[36]. Marteau P, Pochart P, Flourie B, et al. Effect of chronic ingestion of a fermented dairy product containing Lactobacillus acidophilus and Bifidobacterium bifidum on metabolic activities of the colonic flora in humans. Am J Clin Nutr 1990; 52:685-8.

[37]. Midvedt T, Norman A. Bile acid transformation by microbial strains belonging to genera found in intestinal contents. Acta Pathol Microbiol Scand 1967; 7:629-38.

[38]. Snydman, D.R. 2008. The safety of probiotics. Clinical Infectious Diseases 46 (SUPPL. 2).

[39]. Lidbeck A, Nord CE, Gustafsson JA, Rafter J. Lactobacilli,

[40]. Anticarcinogenic activities and human intestinal microflora. Eur J Cancer Prev 1992; 1:341-53.

[41]. Cannon JP, Lee TA, Bolanos JT, Danziger LH. Pathogenic Relevance of Lactobacillus: a retrospective review of over 200 cases. Eur J Clin Microbiol Infect Dis 2005; 24:31-40.

[42]. Spinosa MR, Wallet F, Courcol RJ, Oggioni MR. The trouble in Tracing opportunistic pathogens: cholangitis due to Bacillus in a French hospital caused by a strain related to an Italian probiotic? Microb Ecol Health Dis 2000; 12:99-101.

[43]. Temmerman, R., Pot, B., Huys, G. and Swings, J. 2003. Identification and antibiotic susceptibility of bacterial isolates from probiotic products. International Journal of Food Microbiology 81 (1): 1-10.

[44]. Biocodex USA. Florastor [cited 2009 Oct 24]. http://www.biocodexusa.com/fl orastor.html

[45]. Surawicz CM, McFarland LV, Greenberg RN, Rubin M, Fekety R, Mulligan ME, et al. The search for a better treatment for recurrent Clostridium diffi cile disease: use of high-dose vancomycin combined with Saccharomyces boulardii. Clin Infect Dis. 2000;31:1012-7.

[46]. DOI: $10.1086 / 318130$

[47]. Salminen MK, Tynkkynen S, Rautelin H, et al. The efficacy and safety of probiotic Lactobacillus rhamnosus GG on prolonged, non-infectious diarrhea in HIV patients on antiretroviral therapy: a randomized, placebo-controlled, crossover study. HIV Clin Trials

[48]. 2004; 5:183-91.

[49]. Doron S, Snydman DR, Gorbach SL. Lactobacillus GG: Bacteriology and clinical applications. Gastroenterol Clin North Am 2005; 34: 483-98, ix.

[50]. Doron S, Gorbach SL. Probiotics: their role in the treatment and prevention of disease. Expert Rev Anti Infect Ther 2006; 4:261-75.

[51]. Silva M, Jacobus NV, Deneke C, Gorbach SL. Antimicrobial Substance from a human Lactobacillus strain. Antimicrob Agents Chemother 1987; 31:1231-3.

[52]. Salminen MK, Tynkkynen S, Rautelin H, et al. Lactobacillus Bacteremia during a rapid increase in probiotic use of Lactobacillus rhamnosus GG in Finland. Clin Infect Dis 2002; 35:1155-60.

[53]. Salminen MK, Rautelin H, Tynkkynen S, et al. Lactobacillus bacteremia, species identification, and antimicrobial susceptibility of 85 blood isolates. Clin Infect Dis 2006; 42:e35-44.

[54]. Swenson JM, Facklam RR, Thornsberry C. Antimicrobial susceptibility of vancomycin-resistant Leuconostoc, Pediococcus, and Lactobacillus species. Antimicrob Agents Chemother 1990; 34:543-9.

[55]. Meruman J H, Stamatova I. Probiotics;Contribution To Oral Health. Oral Dis.2007; 13:443-451.

[56]. Burton JP, Chilcott CN, Tagg JR .The rationale and potential for the reduction of oral malodour using Streptococcus salivarius probiotics. Oral Dis.2005; 11 (Suppl. 1): 29-31.

[57]. Kang M-S, Kim B-G, Lee H-C, Oh J-S. Inhibitory effect of Weissella cibaria isolates on the production of volatile sulphur compounds. J Clin Periodontol. 2006; 33: 226-232.

[58]. Lima LM, Motisuki C, Spolidorio DM, Santos-Pintol L. In vitro evaluation of probiotics microorganisms adhesion to an artificial caries model. Eur J Clin Nutr. 2005; 59:884-886.

[59]. Mackay AD, Taylor MB, Kibbler CC, Hamilton-Miller JM. Lactobacillusendocarditis caused by a probiotic organism. Clin Microbiol Infect1999;5:290-2.

[60]. MeurmanJH.Probiotics: do they have a role in oral medicine and dentistry? Eur J Oral Sci 2005;113: 188-196.

[61]. Shantanu Choudhari, Viddyasagar Mopgar, Sneha Sakhare, Namrata Patil. Probiotic way of dental caries prevention. IJCD • JANUARY, $2011 \cdot 2(1)$. 
Table 1. Clinical cases in which lactic acid bacteria or bifidobacteria have been isolated (28)

\begin{tabular}{|l|l|l|l|l|}
\hline Clinical outcome & Endocarditis & Bacteremia & $\begin{array}{l}\text { Other } \\
\text { infection }\end{array}$ & Total \\
\hline Lactobacillus & 7 & 8 & 19 & 34 \\
\hline L. acidophilus & 3 & 3 & 2 & 8 \\
\hline L. casei & 12 & - & - & 12 \\
\hline L. plantarum & 1 & 2 & 1 & 14 \\
\hline L. rhamnosus & 19 & 5 & 3 & 27 \\
\hline Bifidobacterium & - & 9 & - & 9 \\
\hline Leuconostoc & 2 & 23 & 8 & 33 \\
\hline Pediococcus & - & 11 & 7 & 18 \\
\hline Total & 54 & 61 & 40 & 155 \\
\hline
\end{tabular}

Table 2. CONCERNS RELATED TO ORAL HEALTH $(53,54)$

\begin{tabular}{|l|l|}
\hline Meurmann et al $\mathbf{2 0 0 5}$ & Research Needed \\
\hline Natural existence in oral cavity & Screening the oral micoflora \\
\hline Colonization in the mouth & Microbiological \& chemical studies \\
\hline Effect on biofilm \& resistant flora & In vitro \& in Vivo studies \\
\hline Effect on mucosal integrity & In vitro \& in Vivo studies \\
\hline Age dependent colonization & Microbiological studies \\
\hline Role in dental caries & Randomized controlled trails \\
\hline Best way of installation & Randomized controlled trails \\
\hline Synergistic combination of strains & In vitro \& in vivo randomized controlled trails. \\
\hline
\end{tabular}

